2008-09-05

\title{
Control of Double Fed Induction Generator Wind Turbine During Network Voltage Unbalance Conditions
}

Joseph Kearney

Technological University Dublin, joseph.kearney@tudublin.ie

Michael Conlon

Technological University Dublin, michael.conlon@tudublin.ie

Follow this and additional works at: https://arrow.tudublin.ie/engscheleart

Part of the Electrical and Electronics Commons, and the Power and Energy Commons

\section{Recommended Citation}

Kearney, Joseph and Conlon, Michael, "Control of Double Fed Induction Generator Wind Turbine During Network Voltage Unbalance Conditions" (2008). Conference papers. 220.

https://arrow.tudublin.ie/engscheleart/220

This Conference Paper is brought to you for free and open access by the School of Electrical and Electronic Engineering at ARROW@TU Dublin. It has been accepted for inclusion in Conference papers by an authorized administrator of ARROW@TU Dublin. For more information, please contact arrow.admin@tudublin.ie, aisling.coyne@tudublin.ie, gerard.connolly@tudublin.ie.

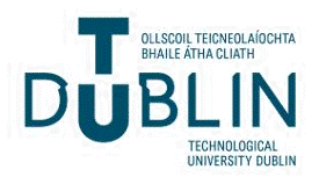




\section{Control of Double Fed Induction Generator Wind Turbine During Network Voltage Unbalance Conditions}

\author{
Joseph Kearney \\ Dublin Institute of Technology, Ireland \\ Joseph.kearney@dit.ie
}

\begin{abstract}
The behaviour of Double-Fed Induction Generators to supply network voltage unbalance is investigated. The paper describes a method to control the rotor-side converter in a DFIG when subjected to the effects of network voltage unbalance conditions. A parallel control scheme is implemented to control the positive and negative sequence components independently. A DFIG model is implemented in Matlab/Simulink and simulations show the reduction in power and torque oscillations and a reduction in the high unbalanced currents generated as a result of the applied voltage unbalance.
\end{abstract}

\section{INTRODUCTION}

Usually the most productive sites for the development of wind turbines and wind farms are in remote rural areas where distribution networks can be weak and voltage unbalance can be a common feature. This is certainly the case in Ireland where the majority of the wind energy developments have been on the north and west coast of the island [1]. This is also the region in which the transmission and distribution network is weakest.

Problems of power quality can arise with regard to the connection of embedded generation, including wind generation. Network voltage unbalance is a power quality problem that can affect wind turbines. Voltage unbalance can give rise to excessive unbalanced stator currents in wind generators, causing generators to trip out [11]. The authors have monitored the voltage unbalance at a small wind farm in County Cavan in the Republic of Ireland over an extended period and have gained an insight into the extent and variability of voltage unbalance experienced by wind generation.

This paper looks specifically at the behaviour of a doublefed induction generator (DFIG) in response to a voltage unbalance introduced into the network to which it is connected. Matlab/Simulink is used to model and simulate a DFIG and the behaviour of the induction generator and the grid/rotor converters is investigated. Improvements in the control structures of the rotor side converter are investigated, and simulations performed to outline the improvements in the performance of the DFIG.

\section{SimUlation STUDY}

Induction generators subjected to network voltage unbalance can overheat due to the excessive currents, and mechanical stress can occur due to torque pulsations. The rotor converter in a DFIG is also susceptible to high currents during periods of voltage unbalance.

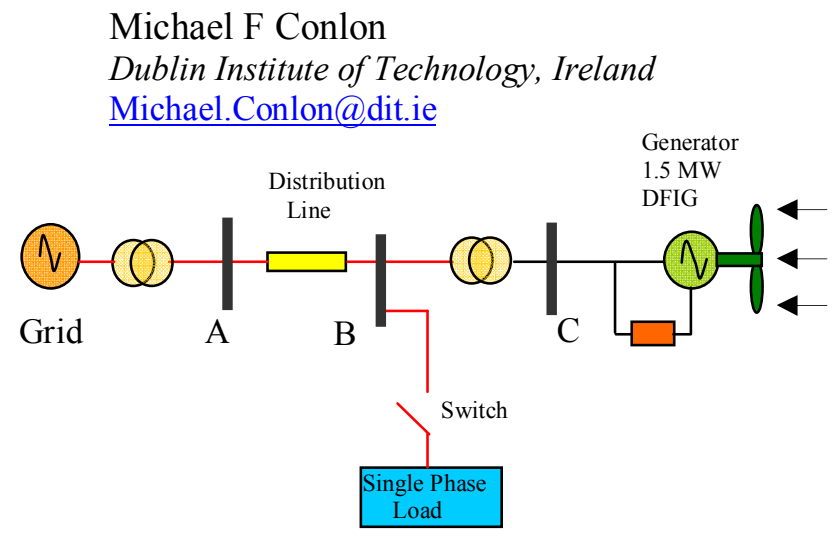

Fig. 1. DFIG and Network Model

The DFIG wind turbine in this study is modelled in Matlab/Simulink [3] to analyse the behaviour of both the induction generator and rotor converter to grid network voltage unbalance. The system under investigation is shown in Fig. 1. The network to which the DFIG is connected is represented by a constant voltage and a distribution line with a length of $30 \mathrm{~km}$. The line series resistance is $0.115 \Omega / \mathrm{km}$ and the reactance is $0.33 \Omega / \mathrm{km}$. The distribution line is operated at a voltage of $25 \mathrm{kV}$, and the fault level at Bus A in Fig. 1 is 30 MVA. The DFIG is connected via a $25 \mathrm{kV} / 690 \mathrm{~V}$ three-phase transformer. The generator rotor is connected to the grid side via a rotor converter, a dc bus $(1.2 \mathrm{kV})$ and a grid side converter. The DFIG has a total rating of $1.5 \mathrm{MVA}$, and for a speed variation of $30 \%$ the rotor converter has a rating $30 \%$ of the induction generator.

As shown in Fig. 1, a single-phase load of 4 MVA is supplied at bus B. This single-phase load introduces a voltage unbalance of $7 \%$ at Bus B. The voltage unbalance is expressed as the ratio of the negative sequence voltage to the positive sequence voltage [4].

\section{Method OF CONTROLling DFIG DURING VOLTAGE UNBALANCE CONDITIONS}

The DFIG consists of an induction generator and a back-toback PWM converter. Network voltage unbalance not only affects the induction generator but also the PWM converter in the rotor [11]. The PWM converter in the rotor consists of a rotor side converter and a grid side converter connected by a dc link bus. The rotor side converter normally controls the real power and reactive power supplied to the network, whereas the grid side converter controls the dc link bus voltage and can also influence the power factor [2]. 

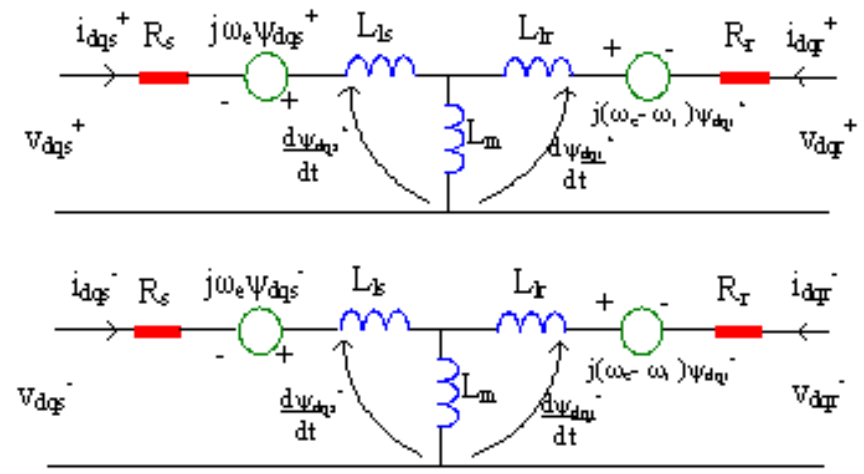

Fig. 2. Positive and Negative Sequence $V_{d q s}$ Equivalent Circuits, (Appendix A lists the parameters)

To reduce the power and torque pulsations as a result of network voltage unbalance it is necessary to modify the control structure of the rotor side converter. The traditional control structure of a DFIG can be modified to incorporate routines for positive and negative sequence control $[5,8]$. The idea is to control the positive and negative sequence components independently.

To modify the control scheme it is necessary to investigate the control of the rotor side and grid side converters. Modification of the rotor side control scheme can help improve the effects of power pulsations and modification of the grid-side converter can help reduce the dc voltage pulsations on the dc link. This paper concentrates on a control scheme for the rotor-side converter to allow it to compensate for the effects of voltage unbalance.

In an unbalanced network the stator apparent power can be expressed in terms of positive and negative sequence components $[5,6,7]$. Due to these components it is necessary to analyse the DFIG per-phase equivalent circuit in the positive and negative sequence dq reference frames, shown in Fig. 2. The positive and negative reference frames can be described by Fig. 3. In Fig. 3 the relationship shows that for the positive sequence $\mathrm{dq}^{+}$reference frame, the $\mathrm{d}^{+}$axis is fixed to the positive voltage rotating at the speed of $\omega_{s}$, whereas for the negative sequence $\mathrm{dq}^{-}$reference frame the $\mathrm{d}^{-}$axis is rotating the speed of $\left(-\omega_{s}\right)$ with the phase angle to the $\alpha$ axis being $\left(-\theta_{e}\right)$. Observing Fig. 3 the transformation between $\alpha \beta$, $d q^{+}$and $d q^{-}$reference frames is given as $[5,7]$ :

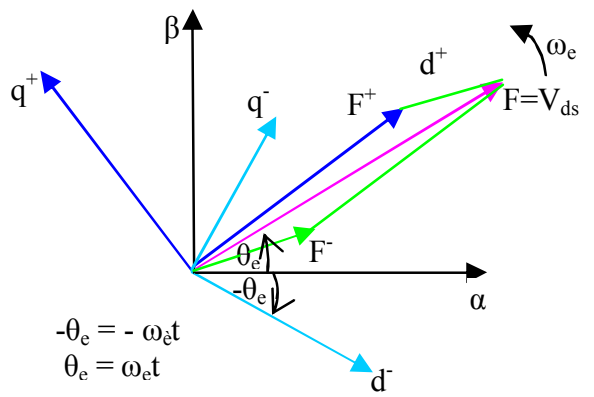

Fig. 3. Positive \& Negative Sequence dq Reference Frames

$$
\begin{aligned}
F_{d q}^{+} & =F_{\alpha \beta} e^{-j \omega_{e} t}, & F_{d q}^{-} & =F_{\alpha \beta} e^{j \omega_{e} t} \\
F_{d q}^{+} & =F_{d q}^{-} e^{-2 j \omega_{e} t}, & F_{d q}^{-} & =F_{d q}^{+} e^{2 j \omega_{e} t}
\end{aligned}
$$

where superscripts $(+)$ and $(-)$ represent the positive and negative sequence reference frames, respectively. Now observing Fig. 3, and (1) and (2) the stator and rotor voltage, current and flux vectors can be expressed using their respective positive and negative sequence components as:

$$
\begin{aligned}
& F_{d q s}^{+}=F_{d q s+}^{+}+F_{d q s-}^{+}=F_{d q s+}^{+}+F_{d q s_{-}}^{-} \cdot e^{-2 j \omega_{e} t} \\
& F_{d q s}^{-}=F_{d q s^{-}}^{-}+F_{d q s+}^{-}=F_{d q s^{-}}^{-}+F_{d q s+}^{+} \cdot e^{2 j \omega_{e} t}
\end{aligned}
$$

where the subscripts $(+)$ and $(-)$ indicate positive and negative sequence components.

\section{ROTOR SIDE CONTROL}

Using the equations for positive and negative sequence voltages and currents the apparent power of the converter can be calculated to improve the effects of voltage unbalance. The stator output apparent power can be described in the positive sequence reference frame as $[5,8]$ :

$$
S=P_{S}+j Q_{S}=-\frac{3}{2} V_{d q s}^{+} I_{d q s}^{+^{*}}
$$

where the superscript $(+)$ indicates the positive sequence reference frame and $V_{d q}{ }^{+}=V_{d}^{+}+j V_{q}^{+}$and $I_{d q}{ }^{+}=I_{d}{ }^{+}+j I_{q}^{+}$. The equation for stator current can be expressed as $[5,6,7]$ :

$$
I_{d q s}^{+}=\frac{1}{\omega_{e} \cdot L_{s}}\left(V_{d q s}^{+}-I_{d q r}^{+} L_{m}\right)
$$

Substituting this value into (4) results in:

$$
P_{S}+j Q_{S}=-\frac{3}{2 \cdot \omega_{e} \cdot L_{s}} V_{d q s}^{+}\left(V_{d q s}^{+*}-I_{d q r}^{+*} L_{m}\right)
$$

If the components in (7) are expressed in terms of positive and negative sequence components in the positive and negative synchronous rotating reference frames, (5) can be expanded as:

$$
S=-\frac{3}{2 L_{s}}\left(\begin{array}{l}
\left(V_{d q s+}^{+}+V_{d q s-}^{-} \cdot e^{-j 2 \omega_{e} t}\right) \cdot\left(I_{d q s+}^{+*}+\left(I_{d q s-}^{-} \cdot e^{-j 2 \omega_{e} t}\right)^{*}\right) \\
-L_{m} \cdot\left(V_{d q s+}^{+}+V_{d q s-}^{-} \cdot e^{-j 2 \omega_{e} t}\right)\left(I_{d q s+}^{+*}+\left(I_{d q s-}^{-} \cdot e^{-j 2 \omega_{e} t}\right)^{*}\right)
\end{array}\right)
$$

When (8) is multiplied out and expanded in term of $d$ and $q$ positive and negative terms, the terms for active and reactive power can be obtained as:

$$
\begin{aligned}
S=P_{s} & +j Q_{s}=\left(P_{s o_{-} a v}+P_{s \sin 2} \sin \left(2 \omega_{s} t\right)+P_{s \cos 2} \cos \left(2 \omega_{s} t\right)\right) \\
& +j\left(Q_{s o_{-} a v}+Q_{s \sin 2} \sin \left(2 \omega_{S} t\right)+Q_{s \cos 2} \cos \left(2 \omega_{s} t\right)\right)
\end{aligned}
$$

where $P_{s o}, P_{s \sin 2 \text {, and }} P_{s} \cos 2$, are the dc average, sine and cosine terms respectively, of twice the network frequency contained in the stator active power. Similarly $Q_{s o}, Q_{s_{-} \sin 2 \text {, }}$ 
and $Q_{s} \cos 2$, are the dc average, sine and cosine terms respectively, of twice the network frequency contained in the stator reactive power. The coefficients of (9) can be described as:

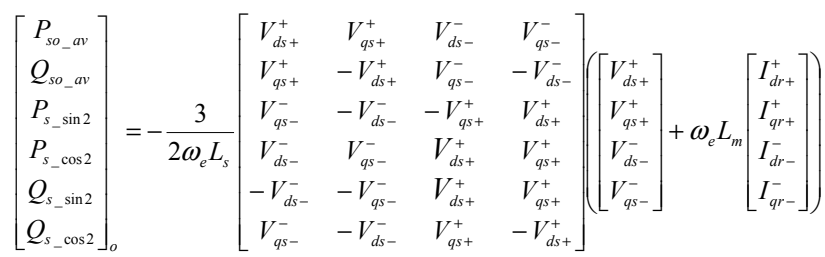

Because the $d^{+}$axis is aligned with the positive sequence stator voltage vector (Fig. 3) the $q$ axis component $V_{q s}{ }^{+}$can be regarded as being equal to zero. In this paper only the real power oscillating components are being investigated and so by allowing $P_{s_{-} \sin 2}=0$ and $P_{s_{-} \cos 2}=0$ in (10) the negative sequence rotor current can be controlled as:

$$
I_{q r-}^{-}=\frac{2 \cdot V_{q s-}^{-}}{\omega_{e} L_{m}}+\frac{1}{V_{d s+}^{+}}\left(V_{d s-}^{-} I_{q r+}^{+}-V_{q s-}^{-} I_{d r+}^{+}\right)
$$

Similarly solving for $I_{d r-}{ }^{-}$yields:

$$
I_{d r-}^{-}=-\frac{2 \cdot V_{d s-}^{-}}{\omega_{e} L_{m}}+\frac{1}{V_{d s+}^{+}}\left(V_{q s^{-}}^{-} I_{q r+}^{+}-V_{d s-}^{-} I_{d r+}^{+}\right)
$$

Compensating terms can also be obtained to control torque pulsations. By analysing the equation for torque, a similar analysis can be progressed and compensating currents $I_{d r-}{ }^{-}$ and $I_{q r-}{ }^{-}$can be obtained to control the sine and cosine torque pulsations $T_{S_{-} \sin 2}$ and $T_{S_{-} \cos 2}$. The electromagnetic torque in a DFIG can be described as:

$$
T_{e}=\frac{3}{2} \frac{p}{L_{s} \omega_{e}}\left(V_{d q s} \cdot I_{d q s}^{*}\right)
$$

Using (6) in (13) yields:

$$
\begin{gathered}
T_{e}=\frac{3}{2} \frac{p}{L_{s} \omega_{e}}\left(V_{d q s}(t) \cdot I_{d q r}^{*}(t)\right) \\
=T_{e o_{-} a v}+T_{e_{-} \sin 2} \sin \left(2 \omega_{e} t\right)+T_{e_{-} \cos 2} \cos \left(2 \omega_{e} t\right)
\end{gathered}
$$

Where the components $T_{\text {eo_av }}, T_{e_{-} s i n 2}$ and $T_{e_{-} \cos 2}$ can be expanded as:

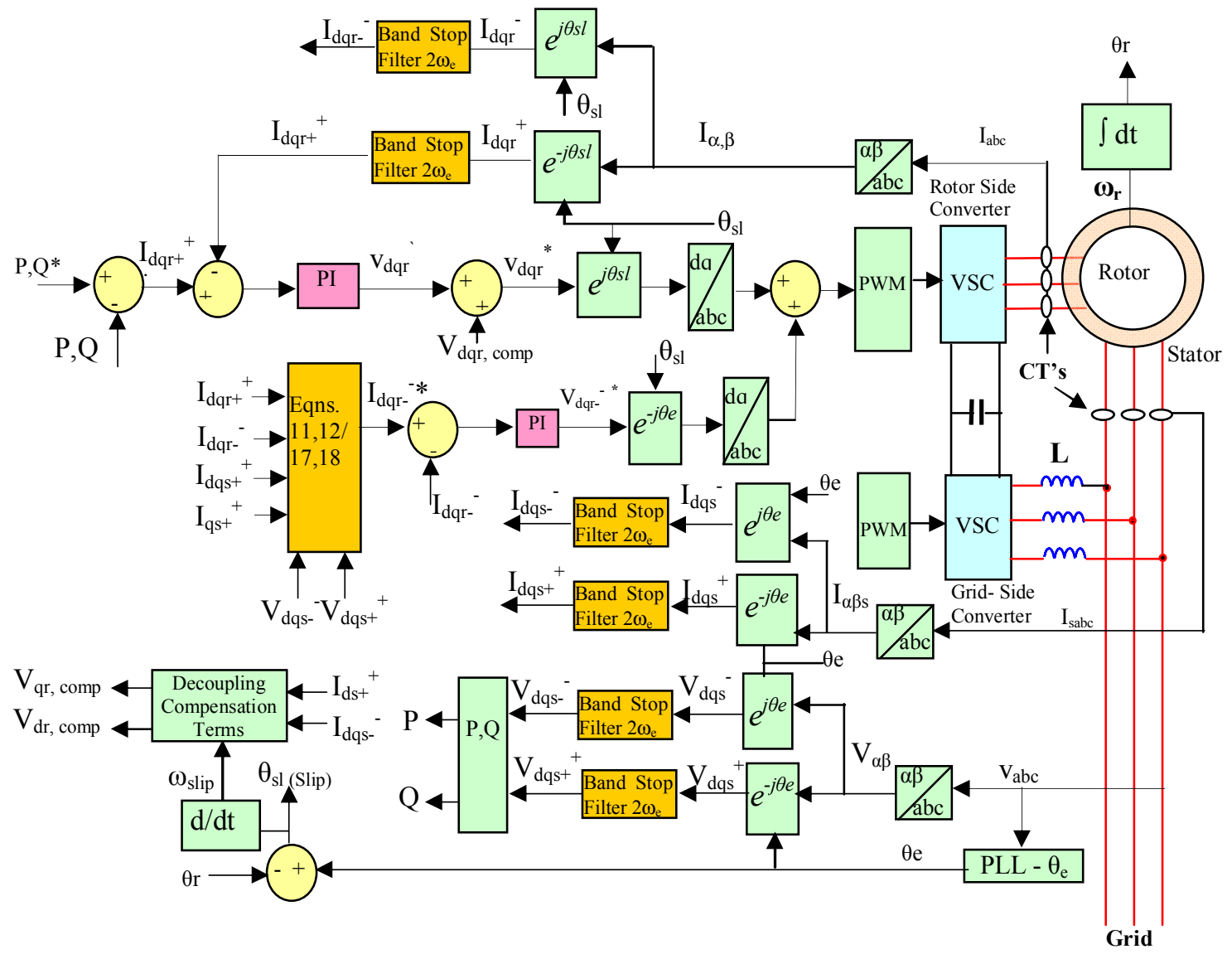

Fig. 4. Rotor Side Converter Parallel Unbalance Control Structure 


$$
\left[\begin{array}{c}
T_{s o_{-} a v} \\
T_{s_{-} \sin 2} \\
T_{s_{-} \cos 2}
\end{array}\right]=-\frac{3 p}{2 \omega_{e} L_{s}}\left[\begin{array}{cccc}
V_{q s+}^{+} & -V_{d s+}^{+} & V_{q s-}^{-} & -V_{d s-}^{-} \\
-V_{d s-}^{-} & -V_{q s-}^{-} & V_{d s+}^{+} & V_{q s+}^{+} \\
V_{q s-}^{-} & -V_{d s-}^{-} & V_{q s+}^{+} & -V_{d s+}^{+}
\end{array}\right]\left[\begin{array}{c}
I_{d r+}^{+} \\
I_{q r+}^{+} \\
I_{d r-}^{-} \\
I_{q r-}^{-}
\end{array}\right]
$$

Because the $\mathrm{d}^{+}$axis is aligned with the positive sequence stator voltage vector (Fig. 3) the $\mathrm{q}$ axis component $\mathrm{V}_{\mathrm{qs}}{ }^{+}$can be regarded as being equal to zero. To reduce the torque pulsations the required control currents can be obtained by allowing $T_{s_{-} \sin 2}=0$ and $T_{s_{-} \cos 2}=0$ in (16). The negative sequence rotor control currents can then be obtained as:

$$
\begin{aligned}
& I_{d r-}^{-}=\frac{1}{V_{d s+}^{+}}\left(V_{d s-}^{-} I_{d r+}^{+}+V_{q s-}^{-} I_{q r+}^{+}\right) \\
& I_{q r-}^{-}=\frac{1}{V_{d s+}^{+}}\left(V_{q s-}^{-} I_{d r+}^{+}-V_{d s-}^{-} I_{q r+}^{+}\right)
\end{aligned}
$$

From (3) and (4), in the $\mathrm{dq}^{+}$reference frame positive sequence components appear as dc values while the negative sequence components oscillate at $2 \omega_{e}$. Whereas in the $\mathrm{dq}$ reference frame negative sequence components appear as $\mathrm{dc}$ values while the positive sequence components oscillate at $2 \omega_{\mathrm{e}}$. Observing Fig. 4 , the stator voltages and currents, and the rotor currents are converted to the $\alpha \beta$ reference frame before transformation to the positive and negative sequence reference frames. This also applies to the $\mathrm{dq}^{-}$reference frame. The stator voltages and currents are then transformed into the positive sequence $\mathrm{dq}^{+}$and negative $\mathrm{dq}^{-}$sequence reference frames, using the angle $\theta_{\mathrm{e}}$ (Fig. 3), obtained with a PLL. The PLL works by controlling the $\mathrm{q}$ axis component to zero. Band-stop (notch) filters tuned at $2 \omega_{\mathrm{e}}$ are then used to remove the oscillating terms, and leave the respective positive and negative sequence $\mathrm{dq}^{+}+$and $\mathrm{dq}^{-}$- components. The positive and negative sequence control voltages $\mathrm{V}_{\mathrm{dqs}^{+}}{ }^{+}$and $\mathrm{V}_{\mathrm{dqs}-}^{-}$, and the positive and negative sequence control currents $\mathrm{I}_{\mathrm{dqs}}{ }^{+}$and $\mathrm{I}_{\text {dqs- }}{ }^{-}$are thus obtained.

Similarly the rotor currents are transformed into the positive sequence $\mathrm{dq}^{+}$and negative $\mathrm{dq}^{-}$sequence reference frames, using the slip angle $\theta_{\mathrm{sl}}$. The slip angle $\theta_{\mathrm{sl}}$ is obtained by subtracting the angle $\theta_{\mathrm{e}}$ form the actual rotor position $\theta_{\mathrm{r}}$. Band-stop (notch) filters tuned at $2 \omega_{\mathrm{e}}$ are then used to remove the oscillating terms, and leave the respective positive and negative sequence $\mathrm{I}_{\mathrm{dqr}}{ }^{+}$and $\mathrm{I}_{\mathrm{dqr}}$ - control currents.

It is also necessary to incorporate positive and negative sequence components, $\mathrm{I}_{\mathrm{dqs}}{ }^{+}+$and $\mathrm{I}_{\mathrm{dqs}}$ - respectively to obtain the necessary decoupling terms, $\mathrm{V}_{\mathrm{d} \text { comp }}$ and $\mathrm{V}_{\mathrm{q}}$ comp. The positive and negative sequence control components are regulated independently before being transformed into the positive sequence reference frame and then summed to form a reference for the PWM controller.

Fig. 5 illustrates the effect of the extraction process to obtain the negative sequence component from the negative sequence reference frame. Fig. 5(a) shows the rotor control current $\mathrm{I}_{\mathrm{dr}}{ }^{-}$(in the negative sequence reference frame) after dq transformation and $5(\mathrm{~b}) \mathrm{I}_{\mathrm{dr}^{-}}{ }^{-}$is the negative sequence component with positive sequence component removed with the notch filter. Fig. 5(c) and (d) shows a similar result for the rotor $\mathrm{q}$ axis negative sequence reference $\mathrm{I}_{\mathrm{qr}}{ }^{-}$, to obtain the negative sequence reference current $\mathrm{I}_{\mathrm{qr}-}{ }^{-}$.

\section{SimUlation RESUlTS}

The control scheme in Fig.4 was implemented in a model in the software program Matlab/Simulink. A timed switch introduced a single-phase load at 0.4 seconds (Fig. 1). At this point it can be observed in Fig. 6(a) that power pulsations as a result of the voltage unbalance occur. The steady state power is set at $(-1.0)$ pu and as observed in Fig 6(a) when voltage unbalance is applied the power oscillates at twice the network frequency $(100 \mathrm{~Hz})$ with peak values of $-0.5 \mathrm{pu}$ and $-1.5 \mathrm{pu}$. The compensation control scheme was timed to start at 0.5 seconds, with the negative sequence currents controlled according to the requirement to minimise power pulsations. It can be observed that after about 0.1 seconds the power oscillations are practically eliminated. Fig. 6(b) shows the three-phase current at the rotor-side converter. At a time 0.4 seconds it can be observed that oscillations are superimposed on the rotor slip frequency of $10 \mathrm{~Hz}$, (rotor speed of $60 \mathrm{~Hz}-$ network frequency of $50 \mathrm{~Hz}$ ). Due to the negative sequence rotation the induced oscillations have a frequency $110 \mathrm{~Hz}(60$ $\mathrm{Hz}+50 \mathrm{~Hz}$ ). Fig. 6(b) shows the reduction in the oscillations after 0.5 seconds when the compensation scheme is introduced.

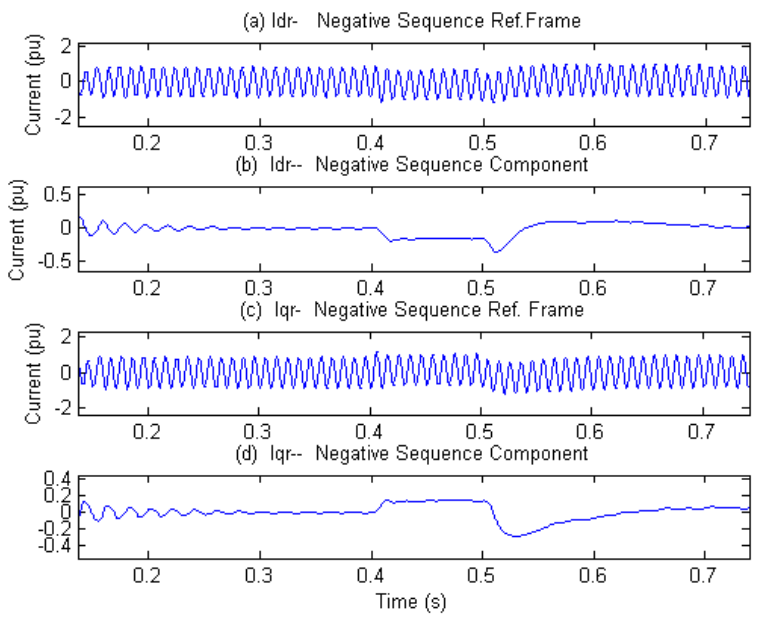

Fig. 5. Id and Iq Negative Sequence Reference Components
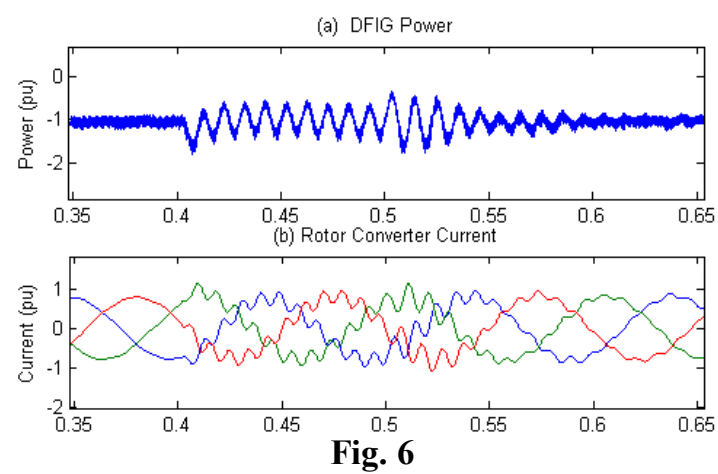
The DFIG stator current unbalance is also improved with the compensation scheme and can be clearly observed in Fig. 7(b).

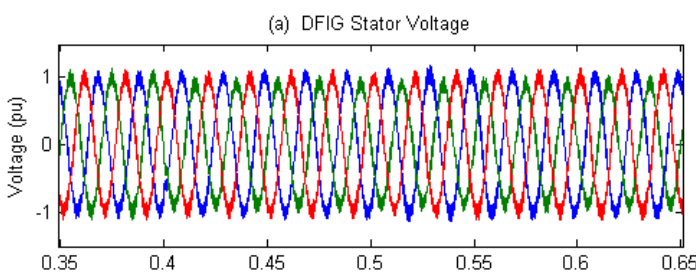

(b) DFIG Stator Current

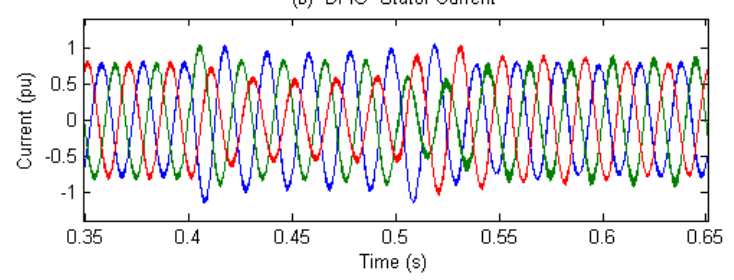

Fig. 7

The torque pulsations can be controlled by using (17) and (18) in the control loop in Fig. 4. When the negative sequence torque control scheme is applied torque pulsations are reduced as shown in Fig. 8.

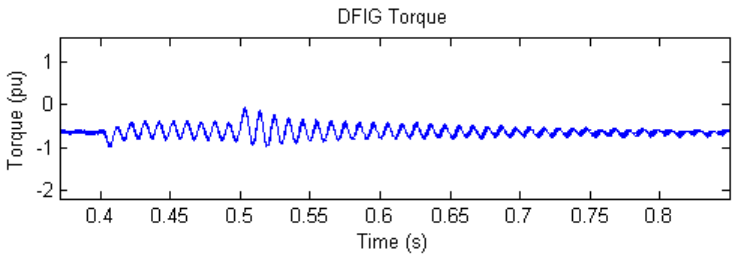

Fig. 8

\section{CONCLUSION}

Control structures for the mitigation of the detrimental effects of voltage unbalance on a DFIG rotor-side converter were investigated. Simulations showed that voltage unbalance when applied to a DFIG can result in large current oscillations in both the induction generator and converter. A model of a DFIG was implemented in Matlab/Simulink to incorporate a compensating control structure for the rotorside converter to reduce power and torque pulsations. The simulation results demonstrate the improvement in the behaviour of the DFIG to network voltage unbalance when compensation structures were introduced. If this type of control were implemented it is clear that an improvement would result in the behaviour of DFIG's during network voltage unbalance conditions.
Appendix A

$V_{\mathrm{dqs}}{ }^{+}, V_{\mathrm{dqs}}{ }^{-}=$Stator dq voltages in the positive and negative sequence reference frames.

$I_{\mathrm{dqs}}{ }^{+}, I_{\mathrm{dqs}}{ }^{-}=$Stator dq currents in the positive and negative sequence reference frames.

$I_{\mathrm{dqr}}{ }^{+}, I_{\mathrm{dqr}}{ }^{-}=$Rotor dq currents in the positive and negative sequence reference frames.

$\psi_{\mathrm{dqs}}{ }^{+}, \psi_{\mathrm{dqs}}{ }^{-}=$Stator dq flux linkages in the positive and negative sequence reference frames

$\psi_{\mathrm{dqr}}{ }^{+}, \psi_{\mathrm{dqr}}^{-}=$Rotor dq flux linkages in the positive and negative sequence reference frames

$R_{\mathrm{s}}=$ Stator winding resistance.

$L_{s}=$ Stator leakage inductance.

$L_{m}=$ Magnetising inductance.

$R_{\mathrm{r}}=$ Rotor referred winding resistance

$L_{\mathrm{r}}=$ Rotor leakage inductance referred to stator.

\section{REFERENCES}

1. M. F. Conlon, M. Basu, N. G. Jayanti, and K. Gaughan, "A Survey of the Installed Wind Generation Capacity in Ireland", 2nd International Conference of Renewable Energy in Maritime Island Climates, 26-28 April 2006, Dublin, Ireland, pp. 55-60

2. A Larson, "The Power Quality of Wind Turbines," PhD. Dept. of Electrical Power Engineering, Chalmers University of Technology, Gothemburg, Sweden 2000.

3. Matlab. The Mathworks Inc.

4. M.F. Conlon and J. Kearney, "Negative Sequence Analysis of Induction Machines" $40^{\text {th }}$ Universities Power Engineering Conference (UPEC), Cork, Ireland, $6^{\text {th }}-9^{\text {th }}$ September 2005

5. Lie Xu, Yi Wang, "Dynamic Modelling and Control of DFIG-Based Turbines Under Unbalanced Network Conditions", IEEE Transactions on Power Systems, 2007. pp 314-323.

6. Yi Wang, Lie Xu, "Control of DFIG-Based Wind Generation Systems under Unbalanced Network Supply", IEEE International, Electrical Machines and Drives Conference, 2007, IEMDC 3-5 ${ }^{\text {th }}$ May '07. pp $430-435$.

7. Jeong-Ik Jang, Young-Sin Kim, "Active and Reactive Power Control of DFIG for Wind Energy Conversion under Unbalanced Grid Voltage", IEEE IPEMC Conference 2006.

8. Hu Jia-bing, He Yi-kang, "Enhanced control of DFIG-using back-toback PWM VSC under unbalanced grid voltage conditions", Journal of Zhejiang University SCIENCE A, China, 2007. pp 1330-1339.

9. Hong-Seok Song, Kwanghee Nam, "Dual Current Control for PWM Converter Under Unbalanced Input Voltage Conditions", IEEE Transactions on Industrial Electronics, vol. 46 no. 5, October 1999, pp 953-959.

10. K Salman, Babak, "New Approach for Modelling Double-Fed Induction Generator (DFIG) for grid-connection studies" European Wind Energy Conference, London. EWEC 22-25 ${ }^{\text {th }}$ Nov. 2004.

11. J Kearney, M. F. Conlon, "Analysis of a Variable Speed Double-Fed Induction Generator Wind Turbine During Network Voltage Unbalance Conditions", $41^{\text {st }}$ Universities Power Engineering Conference (UPEC), Brighton, England, $6^{\text {th }}-9^{\text {th }}$ September 2007. 